\title{
Liver transplantation for alcoholic liver disease among Canadian transplant centres: A national study
}

\author{
Natasha Chandok MD MPH FRCPC ${ }^{1}$, Mohammed Aljawad MD FRCPC ${ }^{1}$, Angela White $\mathrm{PhD}^{2}$, \\ Roberto Hernandez-Alejandro MD FRCPS ${ }^{3}$, Paul Marotta MD FRCPC ${ }^{1}$, Eric M Yoshida MD FRCPC ${ }^{4}$
}

\begin{abstract}
N Chandok, M Aljawad, A White, R Hernandez-Alejandro, P Marotta, EM Yoshida. Liver transplantation for alcoholic liver disease among Canadian transplant centres: A national study. Can J Gastroenterol 2013;27(11):643-646.
\end{abstract}

BACKGROUND/OBJECTIVE: Alcoholic liver disease (ALD) is a controversial yet established indication for liver transplantation (LT), and there is emerging evidence supporting a survival benefit in selected patients with severe acute alcoholic hepatitis. The aim of the present survey was to describe policies among Canadian transplant centres for patients with ALD.

METHODS: A survey was distributed to the medical directors of all seven liver transplant centres in Canada.

RESULTS: All seven liver transplant programs in Canada participated in the survey. Every centre requires patients to have a minimum of six months of abstinence from alcohol before listing for LT. Completion of a rehabilitation program is only mandatory in one program; the remaining programs do not mandate this if patients have demonstrated prolonged abstinence, and sufficient insight and social supports. No program considers LT for patients with severe acute alcoholic hepatitis, although six of the seven programs are interested in exploring a national policy. Random alcohol checks for waitlisted patients are performed routinely on patients listed for ALD at only one centre; the remaining centres only perform checks if there is clinical suspicion. In the past five years, the mean $( \pm S D)$ number of patients per centre with graft dysfunction from recidivism was $10 \pm 4.36$; a mean of $2.5 \pm 4.36$ patients per centre developed graft failure.

CONCLUSIONS: With minor exceptions, LT policies for subjects with ALD are uniform across Canadian transplant programs. Presently, no centres perform LT for acute alcoholic hepatitis, although there is broad interest in exploring a national policy. Recidivism resulting in graft loss is a rare phenomenon.

Key Words: Alcoholic liver disease; Policy; Liver transplantation

4 mong adult Canadians, alcohol, behind only hepatitis $\mathrm{C}$ virus, is Athe second most common etiology of liver disease resulting in liver transplantation (LT). From 2000 to 2009, 487 of 3928 (12.4\%) listed patients in Canada underwent LT for a primary diagnosis of alcoholic liver disease (ALD) (1). While decompensated ALD is an established indication for LT, it remains controversial among factions of society. Although ALD patients experience survival benefits comparable with subjects transplanted for other etiologies of hepatic decompensation, deeply entrenched societal attitudes toward alcoholism render organ transplantation for this patient population a contentious issue in the public forum (2-6).

Because a transplant program must both reflect public values and relentlessly pursue the mandates of beneficence and nonmaleficence to individual patients with organ failure, an inherent conflict may arise in reconciling transplant policies for ALD. The beliefs and perspectives of health care providers comprising the transplant team although not often assessed or accounted for - undoubtedly weigh into
La transplantation du foie en cas de maladie hépatique d'origine alcoolique dans les centres de transplantation canadiens : une étude nationale

HISTORIQUE ET OBJECTIF : La maladie hépatique d'origine alcoolique (MHOA) est une indication controversée, mais établie, de transplantation du foie (TF). Des données émergent pour soutenir les avantages pour la survie de certains patients atteints d'hépatite alcoolique aiguë. La présente étude visait à décrire les politiques des centres de transplantation canadiens à l'égard des patients atteints d'une MHOA. MÉTHODOLOGIE : Les directeurs médicaux des sept centres de transplantation hépatique du Canada ont reçu un sondage.

RÉSULTATS : Les sept centres de transplantation hépatique du Canada ont participé au sondage. Chaque centre exige que le patient s'abstienne de consommer de l'alcool depuis au moins six mois avant de le mettre sur la liste de $\mathrm{TH}$. La participation à un programme de réadaptation est obligatoire dans un seul programme. Les autres programmes ne l'obligent pas si les patients ont démontré une abstinence prolongée, une introspection suffisante et un soutien social. Aucun programme n'envisage la TF pour les patients atteints d'une hépatite alcoolique aiguë, mais six des sept programmes souhaiteraient explorer la possibilité d'une politique nationale. Un seul centre procède systématiquement à un contrôle aléatoire de l'alcool chez les patients inscrits sur la liste d'attente en raison d'une MHOA. Les autres centres effectuent ce contrôle seulement en cas de présomption clinique. Depuis cinq ans, le nombre moyen ( \pm ÉT) de patients par centre présentant une dysfonction de la transplantation en raison d'une récidive s'élevait à $10 \pm 4,36$ cas, tandis qu'une moyenne de $2,5 \pm 4,36$ patients par centre présentaient une insuffisance de la transplantation.

CONCLUSIONS : À quelques exceptions mineures près, les politiques relatives à la $\mathrm{TH}$ chez les sujets atteints d'une MHOA sont uniformes dans tous les programmes de transplantation du Canada. Aucun centre n'effectue de TH pour soigner une hépatite alcoolique aiguë, mais on manifeste un vif intérêt à explorer la possibilité d'une politique nationale à cet égard. Les récidives entraînant la perte de la transplantation sont rares.

medical decision making, including controversial decisions such as adult recipient listing for LT for ALD. At times, the role of the transplant program to do good and to do no harm may conflict with certain sociocultural perspectives that stigmatize and demoralize individuals with alcohol addictions. However, it could be questioned whether what may be perceived to be a health care provider's personal judgment or apparent societal opinions toward alcoholism should influence outcomes of liver organ allocation when patients with ALD would gain clear improvements in longevity and quality of life from a new graft.

LT is life saving and cost effective for selected patients with decompensated cirrhosis, acute liver failure, certain metabolic anomalies and early hepatocellular carcinoma. Most recent one- and five-year survival rates following LT in Canada approximate $92 \%$ and $80 \%$, respectively (1). This success starkly contrasts with outcomes for alcoholic cirrhotic patients with Child-Turcotte-Pugh class $\mathrm{C}$ disease, who have one- and two-year survival rates of just $45 \%$ and $35 \%$, respectively (7), or adults with severe acute alcoholic hepatitis (defined by

${ }^{1}$ Departments of Medicine; ${ }^{2}$ Philosophy; ${ }^{3}$ General Surgery, Western University, London, Ontario; ${ }^{4}$ Department of Medicine, University of British

Columbia, Vancouver, British Columbia

Correspondence: Dr Natasha Chandok, William Osler Health System, 2100 Bovaird Drive East, Brampton, Ontario L6R 2 E9.

Telephone 905-494-2120 ext 57994, fax 905-303-3883, email dr.n.chandok@gmail.com

Received for publication February 20, 2013. Accepted July 3, 2013 
TABLE 1

Survey results

\begin{tabular}{lc}
\hline Policy & $\begin{array}{c}\text { Number of programs } \\
\text { in agreement }\end{array}$ \\
\hline $\begin{array}{c}\text { A mandatory six-month period of abstinence from } \\
\text { alcohol is required before listing for liver transplant }\end{array}$ & 7 of 7 \\
$\begin{array}{l}\text { Mandatory completion of an alcohol rehabilitation } \\
\text { program is required in all recipients with alcoholic }\end{array}$ & 1 of 7 \\
$\quad$ liver disease without exception & \\
$\begin{array}{l}\text { Transplants are performed for selected cases of } \\
\text { severe acute alcoholic hepatitis }\end{array}$ & 0 of 7 \\
$\begin{array}{l}\text { Random alcohol screens are routinely performed on } \\
\text { all patients with alcoholic liver disease awaiting } \\
\text { transplant }\end{array}$ & $\begin{array}{c}1 \text { of } 7 \text { (6 perform } \\
\text { screening only if } \\
\text { clinical suspicion) }\end{array}$ \\
$\begin{array}{l}\text { Validated alcoholism screening tools are routinely } \\
\text { used in the pretransplant assessment }\end{array}$ & 0 of 7 \\
\hline
\end{tabular}

Discriminant Function $>32$ ) who have a $>35 \%$ mortality rate at four weeks. (8)

With respect to chronic liver disease, generally any patient should be considered for LT if there is evidence of hepatic decompensation (clinically defined as evidence of encephalopathy, jaundice, ascites and/or gastrointestinal bleeding from portal hypertension). A survival benefit is noted for well-selected patients with Model for End-stage Liver Disease (MELD) score $>13$ or Child-Turcotte-Pugh class B or C, irrespective of underlying etiology (9). All potential transplant candidates undergo a rigorous evaluation at a transplant centre that includes a hepatic and multisystems workup, cross-sectional abdominal imaging and psychosocial assessments by a multidisciplinary team that includes a transplant hepatologist, hepatobiliary surgeon, anesthesiologist, social worker, psychiatrist or psychologist, dietician and physiotherapist, among other allied health professionals.

In practice, the vast majority of LT programs in North America adhere to a so-called 'six-month rule' for ALD, in which candidates must abstain from alcohol consumption for a minimum of six months, and successfully demonstrate compliance and insight into their addiction in addition to completing a certified alcohol rehabilitation program. This rule effectively eliminates LT for acute alcoholic hepatitis in Canada despite recent evidence for its impressive survival benefit and safety in well-selected candidates (10-12). It also effectively eliminates the newly presented patient with decompensated end-stage cirrhosis who will not survive six months.

Perhaps current policies and attitudes toward patients with ALD stem from the overall shortage of cadaveric grafts, and the realization that living donation can never satisfy society's need for livers, especially considering legitimate safety and/or ethical concerns of the latter. In the previous decade, 907 Canadians died while awaiting LT at Canadian transplant centres (1). It is ultimately the responsibility of transplant programs to be effective stewards of the valuable and limited resource of donated organs, and to save as many lives as possible with the assumption that those who receive the scarce resources will derive long-term benefit.

There is perceived heterogeneity among transplant programs as well as societal attitudes toward LT for ALD, and a specific assessment of policies for LT for ALD at Canadian centres has not been formally explored in the current era of transplantation. Furthermore, there is emerging scientific evidence supporting LT for selected recipients with severe acute alcoholic hepatitis - a concept untested in Canada to date. A national governmental policy (eg, federal government or consensus policy of the provincial Ministries of Health) for LT in this patient group may improve transparency, equality and accountability. The aim of the present survey was to describe practice policies among Canadian transplant centres for patients with ALD. In the absence of a formal national policy, the present survey may also have medicolegal implications in determining what constitutes a 'reasonable standard of care' on this controversial issue.

\section{METHODS}

Following ethics board approval at Western University (London, Ontario), a survey was distributed via secure e-mail or post to the medical directors at all seven liver transplant centres in Canada following informed consent. Results were tabulated and subsequently analyzed qualitatively or using descriptive statistics.

\section{RESULTS}

All of the programs responded to the survey, and each requires a mandatory six-month period of abstinence from alcohol among recipients before listing for LT. Completion of a rehabilitation program is compulsory in only one program; the remaining six programs do not require a recipient to complete a rehabilitation program if the candidate has demonstrated prolonged abstinence for several years, demonstrated insight into their addition and has adequate social supports. No programs presently consider LT for patients with severe acute alcoholic hepatitis, although all programs expressed an interest in a national forum regarding this topic. Random alcohol checks are performed routinely on patients listed for ALD at one centre; the remaining centres only perform alcohol screens if there is clinical suspicion of consumption. Validated alcohol assessment tools are not used by any of the programs, but programs instead rely on the expert opinions of social workers, psychologists or psychiatrists (Table 1).

In the past five years, the estimated mean $( \pm$ SD) number of patients with recidivism per centre resulting in graft dysfunction was $10 \pm 4.36$; the mean number of patients with recidivism resulting in graft failure/loss was 2.5 \pm 2.08 ; the number of patients with mild recidivism was estimated to be 30 in one centre, but not quantifiable in the other six programs. All programs agreed in principle that a nationwide dialogue to further unify transplant policies for ALD patients would be helpful.

\section{DISCUSSION}

Overall, there is homogeneity among Canadian LT programs with respect to transplantation policies for patients with alcohol-related liver disease. All transplant centres in Canada require at least six months of abstinence from alcohol before listing for LT, and none of the centres currently consider LT for severe alcoholic hepatitis or use validated alcohol assessment tools. Interestingly, there is variability in the use of random alcohol checks and reported recidivism rates despite published data to support this practice $(13,14)$. Serious recidivism resulting in graft dysfunction or loss occurs but is uncommon. Importantly, there is uniform consensus among the seven liver transplant programs in Canada to explore a national transplant policy for patients with ALD, although it is suspected that programs would ultimately desire to maintain their autonomy with respect to their centre's ultimate policies. While the present survey provides a useful starting point from which to re-evaluate current policy, it did have some limitations including recall bias in estimating the proportion of ALD patients with recidivism post-LT, and lack of standardized measurements of mild recidivism rates post-LT.

The rationale for the 'six-month rule' is that many subjects with alcoholic hepatitis will improve spontaneously with supportive care (eg, nutritional supplementation, alcohol withdrawal management, prednisone or pentoxyphyline in selected patients, etc) and prolonged abstinence alone, and the majority of hepatic recovery ensues within the first few months (15). An additional reason to justify a mandatory length of sobriety is that prolonged abstinence is a negative predictor of recidivism in the post-LT setting (13,16-18).

In theory, recidivism following LT is relevant because not only could it result in graft loss, but it may have a dire influence on organ donation rates, although it should be noted that there is weak evidence to support this latter hypothesis. Notwithstanding, while rates of alcohol recidivism are approximately $15 \%$ to $25 \%$ post-LT $(14,17,19)$, the majority of patients with a history of ALD consume minimal amounts that are unlikely to cause graft dysfunction (20). The natural history of ALD following LT is poorly understood for the 
obvious reason that there are limited observational data; however, a recent French registry-based study suggested that cirrhosis may recur in as little as 3.5 years (21) and previous Spanish data suggested that patients with recidivism have worse 10 -year survival rates (22). The former observation of an accelerated natural history of ALD post-LT in some recipients may be explained by the concurrent overlap of nonalcoholic fatty liver disease, which is highly prevalent in LT recipients. On the other hand, in theory, alcohol may provide some immuneprotection against rejection, and overall rates of graft loss from recidivism are exceedingly low in multiple publications.

Organ allocation systems are required to fairly and predictably orchestrate organ allotment given the relative deficit of cadaveric grafts compared with the surplus of patients who need them. The MELD model is the most widely used organ allocation system in North America and was formally implemented in the United States (United Network for Organ Sharing) in 2003, and in Canadian liver transplant programs gradually thereafter. In addition to the MELD score being a validated predictor of mortality for subjects with end-stage liver disease or acute liver failure, the model does not overtly discriminate on the basis of age, recipient sex, geographical location, ethnicity or underlying etiology of liver disease, thus satisfying principles of equitable access, universality, transparency and portability.

While organ allocation should be a blinded process to preserve fairness, listing of potential recipients remains under the jurisdiction of the transplant programs in Canada, and this creates an opportunity for selection bias against those with ALD. Given that there are behavioural elements contributing to most liver diseases (with perhaps the exception of liver conditions that are immune mediated or strongly genetic), the question then becomes, do patients with ALD experience barriers to access LT compared with patients with nonalcoholic liver diseases, and is this distinction fair?

For example, consider the scenario of a patient with nonalcoholic fatty liver disease and etiological risk factors that include obesity, hyperlipidemia and type 2 diabetes mellitus. In this setting, one might argue that this patient could have exerted some control over his or her body weight and glycemic management through dietary modifications and exercise to lower his or her risk of end-stage liver disease. Does this line of reasoning justifiably deny listing this patient for LT years later? Similarly, is a former intravenous drug abuser who acquired hepatitis C infection from inadvertently sharing contaminated needles more entitled to LT than a person with ALD? These ethical arguments suggest there may be some inconsistency in the notion that patients with ALD are responsible for their cirrhosis if we do not apply the same logic to other patient groups. Furthermore, there is evidence of a strong genetic role in the pathogenesis of ALD (23); surely patients in a just society should not be penalized for having a genetic predisposition to a potentially fatal disease.

Decisions on organ allocation for subjects with ALD must be transparent and justifiable to society. The transplant community and the Canadian public at large should re-evaluate the 'six-month rule' and weigh mounting evidence of the efficacy of LT for severe acute ALD - effectively much sooner than six months. While successful completion of a rehabilitation program and psychosocial counselling is vitally important for anyone with alcohol addiction, what happens if a patient is too sick to leave the hospital to complete a rehabilitation program? Does that mean he or she dies without an opportunity for LT? Cost-effective arguments against LT in this group are also unlikely to have merit. We have previously shown that subjects with ALD have no increased risk for excess postoperative resource utilization or readmission after LT $(24,25)$. The question with regard to transplant candidacy for patients with ALD should pertain to the likelihood of graft loss from recidivism post-LT and decisions should be evidence based.

\section{CONCLUSION}

Current policies for LT for patients with ALD are similar across Canadian transplant programs, all of which adhere to the 'six-month rule', but there is a desire for further debate and exploration of policies to address acute alcoholic hepatitis. Given emerging evidence supporting the efficacy of LT for both severe acute and chronic ALD, it would be in the interest of transplant programs to spearhead a governmentally sanctioned policy discussion into the topic to provide transparency to the public, and establish a medicolegal framework on which to justify medical decisions on listing or not listing patients. In the absence of such an official policy statement, the present article documents what can be considered a reasonable standard of transplant care in this country.

\section{KEY MESSAGES}

- Among the seven Canadian liver transplant programs, there is overall strong concordance in transplant policies toward patients with ALD with respect to adherence to the 'six-month rule' and no transplantation for severe acute alcoholic hepatitis.

- Canadian transplant policies regarding ALD are consistent with current American and European practices, but there is broad interest, particularly in Europe, toward further evaluation of LT in severe, medically refractory, acute alcoholic hepatitis in light of growing evidence of a survival benefit.

\section{REFERENCES}

1. CIHI. Canadian Organ Replacement Register Annual Report. 2011.

2. Brudney D. Are alcoholics less deserving of liver transplants? Hastings Cent Rep 2007;37:41-7.

3. Glannon W. Responsibility, alcoholism, and liver transplantation. J Med Philos 1998;23:31-49.

4. Gramenzi A, Gitto S, Caputo F, et al. Liver transplantation for patients with alcoholic liver disease: An open question. Dig Liver Dis 2011;43:843-9.

5. Ho D. When good organs go to bad people. Bioethics 2008;22:77-83.

6. Moss AH, Siegler M. Should alcoholics compete equally for liver transplantation? JAMA 1991;265:1295-8.

7. Pugh RN, Murray-Lyon IM, Dawson JL, Pietroni MC, Williams R. Transection of the oesophagus for bleeding oesophageal varices. Br J Surg 1973;60:646-9.

8. Maddrey WC, Boitnott JK, Bedine MS, Weber FL Jr, Mezey E, White RI Jr. Corticosteroid therapy of alcoholic hepatitis. Gastroenterology 1978;75:193-9.

9. Cholongitas E, Marelli L, Shusang, et al. A systematic review of the performance of the model for end-stage liver disease (MELD) in the setting of liver transplantation. Liver Transpl 2006;12:1049-61.

10. Weinrieb RM, Van Horn DH, Lynch KG, Lucey MR. A randomized, controlled study of treatment for alcohol dependence in patients awaiting liver transplantation. Liver Transpl 2011;17:539-47.

11. Mathurin P, Moreno C, Samuel D, et al. Early liver transplantation for severe alcoholic hepatitis. N Engl J Med 2011;365:1790-800.

12. Singal AK, Bashar H, Anand BS, Jampana SC, Singal V, Kuo YF. Outcomes after liver transplantation for alcoholic hepatitis are similar to alcoholic cirrhosis: Exploratory analysis from UNOS database. Hepatology 2012;55:1398-405.

13. Erim Y, Bottcher M, Dahmen U, Beck O, Broelsch CE, Helander A. Urinary ethyl glucuronide testing detects alcohol consumption in alcoholic liver disease patients awaiting liver transplantation. Liver Transpl 2007;13:757-61.

14. Carbonneau M, Jensen LA, Bain VG, Kelly K, Meeberg G, Tandon P. Alcohol use while on the liver transplant waiting list: A single-center experience. Liver Transpl 2010;16:91-7.

15. Singal AK, Shah VH. Alcoholic hepatitis: Prognostic models and treatment. Gastroenterol Clin North Am 2011;40:611-39.

16. Tandon P, Goodman KJ, Ma MM, et al. A shorter duration of pre-transplant abstinence predicts problem drinking after liver transplantation. Am J Gastroenterol 2009;104:1700-6.

17. Hartl J, Scherer MN, Loss M, et al. Strong predictors for alcohol recidivism after liver transplantation: Non-acceptance of the alcohol problem and abstinence of $<3$ months. Scand J Gastroenterol 2011;46:1257-66. 
18. Karim Z, Intaraprasong P, Scudamore $\mathrm{CH}$, et al. Predictors of relapse to significant alcohol drinking after liver transplantation. Can J Gastroenterol 2010;24:245-50.

19. Gedaly R, McHugh PP, Johnston TD, et al. Predictors of relapse to alcohol and illicit drugs after liver transplantation for alcoholic liver disease. Transplantation 2008;86:1090-5.

20. Mackie J, Groves K, Hoyle A, et al. Orthotopic liver transplantation for alcoholic liver disease: A retrospective analysis of survival, recidivism, and risk factors predisposing to recidivism. Liver Transpl 2001;7:418-27.

21. Cannesson A. Prevalence and natural history of recurrent alcoholic cirrhosis after liver transplantation. American Association for the Study of Liver Disease Meeting. Boston, November 9 to 13, 2012. (Abst)
22. Cuadrado A, Fabrega E, Casafont F, Pons-Romero F. Alcohol recidivism impairs long-term patient survival after orthotopic liver transplantation for alcoholic liver disease. Liver Transpl 2005;11:420-6.

23. Wilfred de Alwis NM, Day CP. Genetics of alcoholic liver disease and nonalcoholic fatty liver disease. Semin Liver Dis 2007;27:44-54.

24. Shankar N, AlBasheer M, Marotta P, Wall W, McAlister V, Chandok N. Do older patients utilize excess health care resources after liver transplantation? Ann Hepatol 2011;10:477-81.

25. Shankar N, Marotta P, Wall W, AlBasheer M, Hernadez-Alejandro R, Chandok N. Defining readmission risk factors for liver transplantation recipients. Gastroenterol Hepatol 2011;7:585-90. 


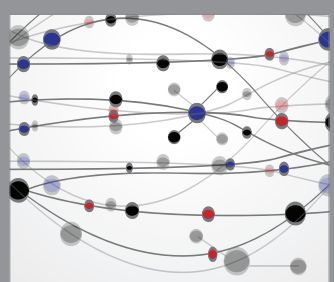

The Scientific World Journal
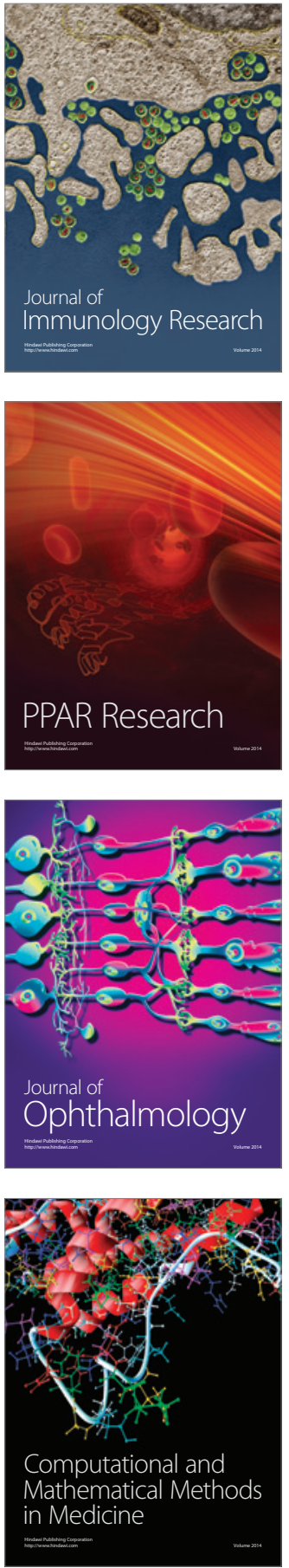

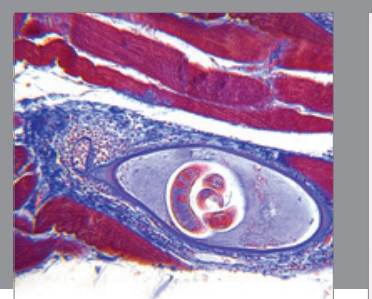

Gastroenterology Research and Practice

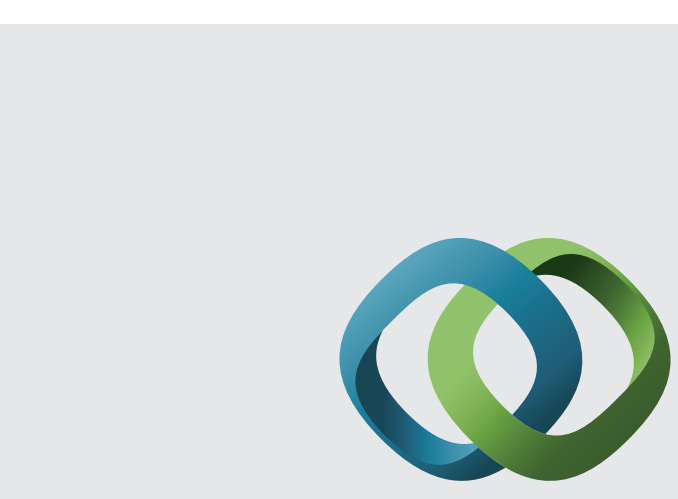

\section{Hindawi}

Submit your manuscripts at

http://www.hindawi.com
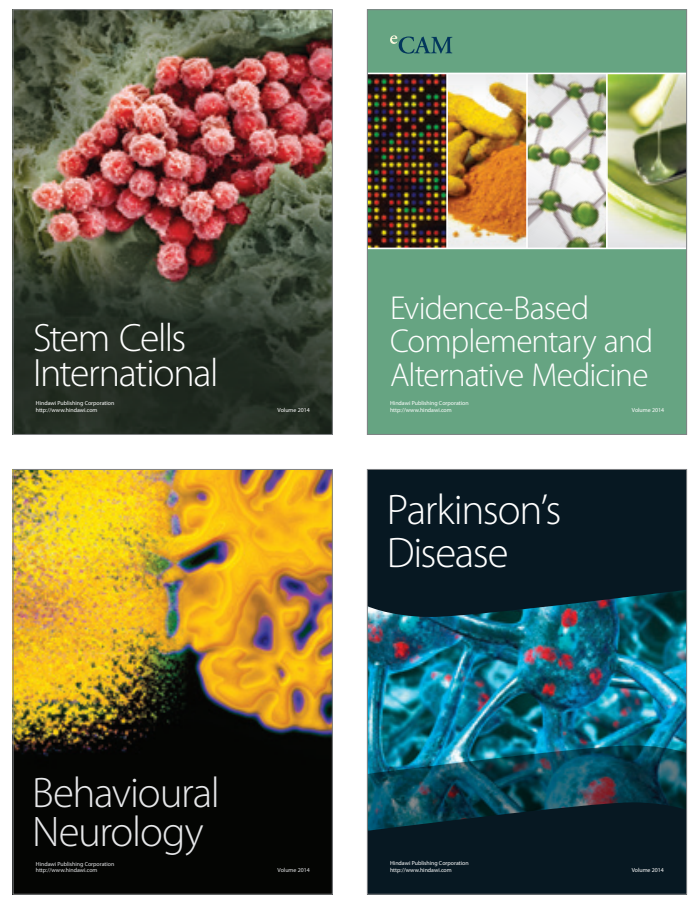
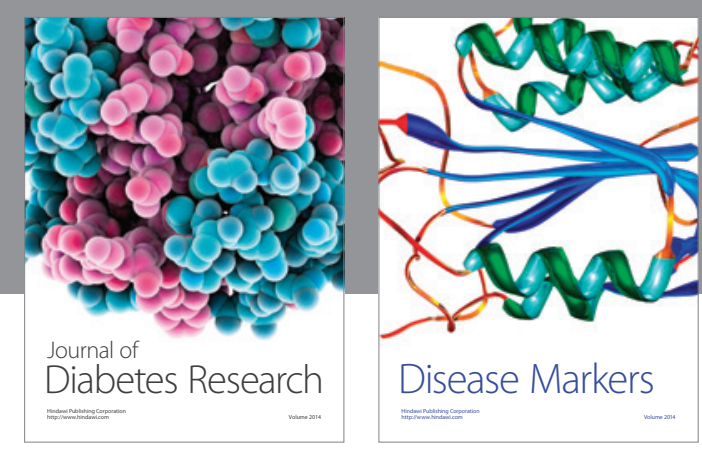

Disease Markers
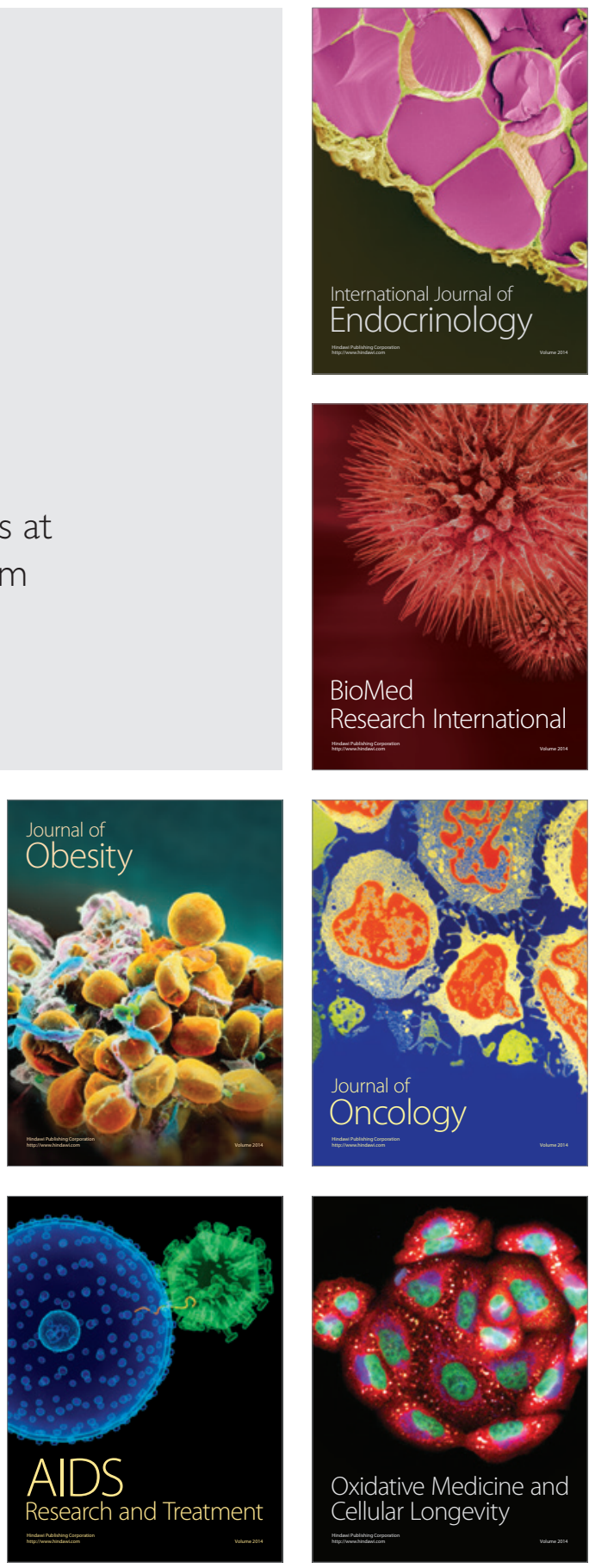